\title{
Correction to: Active Tuning from Narrowband to Broadband Absorbers Using a Sub-wavelength V02 Embedded Layer
}

\author{
Ataollah Kalantari Osgouei ${ }^{1,2} \cdot$ Hodjat Hajian $^{2} \cdot$ Bahram Khalichi $^{2,3} \cdot$ Andriy E. Serebryannikov $^{2,4} \cdot$ Amir Ghobadi $^{2,3}$. \\ Ekmel Ozbay ${ }^{1,2,3,5}$
}

Published online: 4 February 2021

๑) Springer Science+Business Media, LLC, part of Springer Nature 2021

\section{Correction to: Plasmonics \\ https://doi.org/10.1007/s11468-020-01370-w}

The original version of this article unfortunately contained a mistake. The name of the fourth author is written reversely. The complete name of the fourth author is as follows: "Andriy E." as the first name, while "Serebryannikov" is his last name. The original article has been corrected.

Publisher's Note Springer Nature remains neutral with regard to jurisdictional claims in published maps and institutional affiliations.

The original article can be found online at https://doi.org/10.1007/ s11468-020-01370-w.

Ataollah Kalantari Osgouei akalantari@bilkent.edu.tr

1 Department of Physics, Bilkent University, 06800 Ankara, Turkey

2 NANOTAM- Nanotechnology Research Center, Bilkent University, Ankara 06800, Turkey

3 Department of Electrical and Electronics Engineering, Bilkent University, Ankara 06800, Turkey

4 Faculty of Physics, Adam Mickiewicz University, 61-614 Poznan, Poland

5 UNAM-Institute of Materials Science and Nanotechnology, Bilkent University, Ankara, Turkey 